CLINICAL STUDY

\title{
Changes in circulating level of IGF-I and IGF-binding protein-1 from the first to second trimester as predictors of preeclampsia
}

\author{
Lars J Vatten, Tom I L Nilsen, Anders Juul ${ }^{1}$, Stig Jeansson ${ }^{2}$, Pål A Jenum ${ }^{3}$ and Anne Eskild ${ }^{4,5}$ \\ Department of Public Health, Norwegian University of Science and Technology, NO-7489 Trondheim, Norway, ${ }^{1}$ Department of Growth and Reproduction, \\ Rigshospitalet, University of Copenhagen, Copenhagen, Denmark, ${ }^{2}$ Department of Microbiology, Ullevål University Hospital, Oslo, Norway, ${ }^{3}$ Department \\ of Microbiology, Asker and Barum Hospital, Barum, Norway, ${ }^{4}$ Division of Mental Health, Norwegian Institute of Public Health, Oslo, Norway and \\ ${ }^{5}$ Department of Obstetrics and Gynecology and Faculty of Medicine, Akershus University Hospital, University of Oslo, Lorenskog, Norway \\ (Correspondence should be addressed to L J Vatten; Email: lars.vatten@ntnu.no)
}

\begin{abstract}
Objective: To assess whether circulating IGF-I and IGF-binding protein-1 (IGFBP-1) in the first and second trimester are associated with subsequent risk of preterm and term preeclampsia.

Methods: Nested case-control study within a cohort of 29948 pregnant women. Cases were women, who later developed preeclampsia, and controls were randomly selected women, who did not develop preeclampsia. IGF-I and IGFBP-1 were measured with ELISA in maternal blood samples that were collected in the first and second trimesters. We assessed associations of IGF-I and IGFBP-1 concentrations with later development of preterm (before the 37 th week of gestation) and term preeclampsia.

Results: An increase in IGF-I from the first to second trimester was associated with higher risk of preterm preeclampsia; the odds ratio $(\mathrm{OR})$ for the highest compared with lowest quartile of increase was 4.9 (95\% confidence interval, 1.1-21.8). Low concentrations of IGFBP-1, both in the first and in the second trimesters, were related to higher risk of term preeclampsia (OR 4.0, 95\% confidence interval, 1.9-8.4) and moderately increased risk of preterm preeclampsia (OR 2.3, 95\% confidence interval, 1.2-4.4).

Conclusion: The higher risk of preterm preeclampsia related to IGF-I increase may reflect placental disease, whereas low concentrations of IGFBP-1 associated with term preeclampsia may reflect maternal metabolic aberrations, indicating different etiologies in preeclampsia.
\end{abstract}

European Journal of Endocrinology 158 101-105

\section{Introduction}

Preeclampsia complicates $3-5 \%$ of first pregnancies and globally is a major cause of maternal and infant morbidity and mortality (1). The etiology is unknown, but abnormal placentation and maternal endothelial dysfunction precede the clinical characteristics of hypertension and proteinuria $(1,2)$.

In normal pregnancies, maternal serum levels of insulin-like growth factor-I (IGF-I) increase from about the 20th week of pregnancy (3). The increase is probably induced by placental production of a specific growth hormone $(\mathrm{GH})$ variant (placental $\mathrm{GH})$, where the effects of placental GH on fetal growth are likely to be mediated via circulating maternal IGF-I (3).

The biological activity of IGF-I is influenced by IGFbinding proteins (IGFBPs) to which the majority of IGF-I is bound, leaving only a fraction in its free, biologically active form. In the non-pregnant state, IGFBP-1 is produced in the liver and is strongly regulated by insulin. In pregnancy, IGFBP-1 is also produced in the placenta, resulting in higher maternal concentrations of this protein.
It is not known whether maternal IGFs in early pregnancy are associated with subsequent development of preeclampsia. However, the IGF system is thought to play a role in abnormal placentation, where high decidual production of IGFBP-1 may block IGF-I activity and reduce trophoblast invasion (4). It has therefore been suggested that women who later develop preeclampsia may have a lower concentration of IGF-I and a higher concentration of IGFBP-1 in early pregnancy compared with other pregnant women (4). However, the results of previous studies are not consistent with this hypothesis. Whereas some studies show higher concentrations of IGF-I and lower concentrations of IGFBP-1 in women, who later developed preeclampsia (5-8), other studies have shown the opposite (4). Furthermore, it is not known whether changes in IGF-I concentration from first to second trimester are related to later development of preeclampsia.

In this nested case-control study within a large population of pregnant women, we therefore assessed whether maternal IGF-I and IGFBP-1 levels, as single measurements in the first and second trimesters, and 
changes between trimesters, predict subsequent development of preterm or term preeclampsia.

\section{Materials and methods}

Between June 1992 and May 1994, 35940 women in Norway participated in a prospective study of Toxoplasma gondii infection in pregnancy. All pregnant women who attended antenatal care in 11 out of 19 counties were included in the study (9). Subsequent to the original study, we attempted to contact all participating women by mail to obtain their consent to use the data and blood samples for additional scientific purposes, and 29948 women consented.

We obtained information on pregnancy outcomes from the Medical Birth Registry of Norway (www.uib.no/mfr), which has recorded information on all births in the country since 1967. Information on each pregnancy was obtained by compulsory notification on standardized forms by delivering midwives, including information on maternal and fetal health. The diagnosis of preeclampsia in the Medical Birth Registry was based on the development of hypertension and proteinuria after 20 weeks of pregnancy, including blood pressure above $140 / 90 \mathrm{mmHg}$ and proteinuria (protein dip stick $\geq 1+$, or $\geq 0.3 \mathrm{~g} / 24 \mathrm{~h}$ ). The mean age at childbearing was 29 years (S.D. 5.3 years), $41 \%$ were nulliparous, $36 \%$ primiparous, and $23 \%$ of the women had two or more previous births.

From the cohort of 29948 women, 107 women, who later developed preeclampsia, had blood drawn during the first trimester and had a premature delivery (gestational week $<37$ of pregnancy). These cases were classified as having 'preterm preeclampsia'. Among women who had blood drawn during the second trimester, 108 were classified as preterm preeclampsia. Among cases with preterm preeclampsia, 42 women had blood drawn from both trimesters, allowing analyses of changes from the first to the second trimester.

In the cohort as a whole, another 766 women were diagnosed with preeclampsia, but delivered at term. Among these cases, we selected 143 with term preeclampsia who had blood drawn during the first trimester, and 128 who had blood drawn in the second trimester. Of these cases, 47 women had blood drawn from both trimesters.

Among women in the cohort who did not develop preeclampsia, we used 274 who had blood drawn from the first trimester as controls, and 286 who had drawn blood from the second trimester. Among these controls, 95 women had blood drawn in both the trimesters.

The study was approved by the Norwegian Directorate for Health and Social Affairs, the Norwegian Data Inspectorate, and the Regional Committee for Medical Research Ethics.

\section{Serum analyses of IGF-I and IGFBP-1}

In the first trimester, serum was collected at approximately the 9th week of gestation (median 9, ranges 4-12 weeks), and in the second trimester, serum was collected around the 22nd week (median, 22; ranges 19-27 weeks).

The sera were treated according to uniform standards and stored in one place at $-20^{\circ} \mathrm{C}$ until analysis. The concentrations of IGF-I and IGFBP-1 were determined by ELISA (DSL-10-2800 Non-Extraction IGF-I ELISA; DSL-10-7800 TOTAL IGFBP-1, ELISA, both from Diagnostics Systems Laboratories Inc., Webster, TX, USA) according to the manufacturer's instructions. The non-extraction IGF-I ELISA has been shown to yield results equal to those of the extraction assay (10). The IGF-I ELISA has a minimum detection limit of $2.06 \mathrm{ng} / \mathrm{ml}$ (which is the sensitivity according to the DSL kit insert for the non-extraction assay), and the IGFBP-1 ELISA has a minimum detection limit of $0.25 \mathrm{ng} / \mathrm{ml}$. The intra-assay coefficient of variation (CV) for IGF-I was $6.3-8.6 \%$ and the inter-assay $\mathrm{CV}$ was $3.3-6.8 \%$. For IGFBP-1, the corresponding CVs were 1.7-4.6 and $6.2-7.6 \%$, as reported by the manufacturer. Samples with concentrations below the detection limits of the respective hormone assays were assigned the minimal detection value. The technicians performing the hormone analyses were blinded to the clinical outcome.

\section{Statistical analysis}

We assessed the association between circulating IGFs and the subsequent risk of preeclampsia, both as single measurements within trimesters and as changes in IGFs from the first to the second trimester. Based on the distribution among controls, we divided concentrations of IGF-I and IGFBP-1, both within and between trimesters, into quartiles, and used odds ratio (OR) to assess the association between quartiles of IGF-I and IGFBP-1 and risk of preterm or term preeclampsia.

We used multiple logistic regression to adjust for potential confounding by maternal age and parity, and time interval (in weeks) between serum collections. All statistical analyses were performed using the Statistical Package for the Social Sciences (version 13.0; SPSS Inc., Chicago, IL, USA).

\section{Results}

\section{IGF-I and subsequent preeclampsia}

There was no clear association between the serum IGF-I levels within each trimester and the subsequent risk of preterm or term preeclampsia (Table 1). However, the increase in IGF-I concentration between trimesters was associated with a higher risk of preeclampsia. Comparing women in the highest quartile of increase in IGF-I with women in the lowest quartile of increase, 
Table 1 The association (odds ratios, OR) between quartiles of concentrations of insulin-like growth factor-I (IGF-I) and subsequent preeclampsia (diagnosed preterm or at term).

\begin{tabular}{|c|c|c|c|c|c|c|c|}
\hline \multirow[b]{2}{*}{ IGF-I (ng/ml) } & \multirow[b]{2}{*}{ Controls } & \multicolumn{3}{|c|}{ Preterm $^{a}$ preeclampsia } & \multicolumn{3}{|c|}{ Term ${ }^{a}$ preeclampsia } \\
\hline & & Cases & $\mathrm{OR}^{\mathrm{b}}$ & $(95 \% \mathrm{Cl})$ & Cases & $\mathrm{OR}^{\mathrm{b}}$ & $(95 \% \mathrm{Cl})$ \\
\hline \multicolumn{8}{|l|}{ First trimester } \\
\hline$<83.49$ & 69 & 30 & 1.0 & (Reference) & 38 & 1.0 & (Reference) \\
\hline $83.49-144.65$ & 68 & 26 & 1.0 & $(0.5-1.9)$ & 28 & 0.7 & $(0.4-1.3)$ \\
\hline $144.66-241.50$ & 69 & 29 & 1.1 & $(0.6-2.1)$ & 41 & 1.1 & $(0.8-3.2)$ \\
\hline$\geq 241.51$ & 68 & 22 & 0.8 & $(0.4-1.7)$ & 36 & 1.0 & $(0.5-1.9)$ \\
\hline \multicolumn{8}{|l|}{ Second trimester } \\
\hline$<84.00$ & 72 & 29 & 1.0 & (Reference) & 31 & 1.0 & (Reference) \\
\hline $84.00-126.90$ & 71 & 15 & 0.6 & $(0.3-1.2)$ & 21 & 0.8 & $(0.4-1.6)$ \\
\hline $126.91-195.60$ & 72 & 25 & 1.0 & $(0.5-1.9)$ & 24 & 0.8 & $(0.4-1.6)$ \\
\hline$\geq 195.61$ & 71 & 39 & 1.5 & $(0.8-2.8)$ & 52 & 1.8 & $(1.0-3.3)$ \\
\hline \multicolumn{8}{|c|}{ Change from first to } \\
\hline \multicolumn{8}{|c|}{ second trimester } \\
\hline$<33.21$ & 24 & 3 & 1.0 & (Reference) & 7 & 1.0 & (Reference) \\
\hline $33.21-67.20$ & 24 & 9 & 2.2 & $(0.4-10.6)$ & 9 & 1.6 & $(0.5-5.7)$ \\
\hline $67.21-133.83$ & 24 & 14 & 4.5 & $(1.0-20.1)$ & 14 & 2.3 & $(0.7-7.4)$ \\
\hline$\geq 133.84$ & 23 & 16 & 4.9 & $(1.1-21.8)$ & 17 & 2.9 & $(0.9-9.2)$ \\
\hline
\end{tabular}

$\mathrm{Cl}$ denotes confidence interval.

${ }^{\text {a }}$ Preterm preeclampsia; diagnosed at gestational week 37 or earlier. Term preeclampsia; diagnosed after week 37.

${ }^{b}$ Adjusted for gestational week of blood sampling (continuous), maternal age $(<25,25-29,30-34, \geq 35$ years), and parity ( $1,2, \geq 3$ ).

the OR was 2.9 (95\% confidence interval, 0.9-9.2) for term preeclampsia, and 4.9 (95\% confidence interval, 1.1-21.8) for preterm preeclampsia.

\section{IGFBP-1 and subsequent preeclampsia}

Low level of IGFBP-1, both in the first and the second trimesters, was associated with higher risk of term, but not preterm preeclampsia. By comparing the lowest and highest quartiles of IGFBP-1 in the first trimester (Table 2), the OR for preterm preeclampsia was 1.5 (95\% confidence interval, 0.7-3.3) compared with 4.0 (95\% confidence interval, 1.9-8.4) for term preeclampsia. In the second trimester, the results were similar; the OR for preterm preeclampsia was 1.7 (95\% confidence interval, 0.9-3.1) and for term preeclampsia, the OR was 2.3 (95\% confidence interval, 1.2-4.4) for women in the lowest, compared with the highest quartile of IGFBP-1.

The change in concentration of IGFBP-1 from the first to the second trimester was not consistently associated with the subsequent development of preeclampsia.

\section{Discussion}

In this large nested case-control study, we found that a relatively high increase in the concentration of IGF-I in maternal serum from the first to the second trimester was associated with a highly increased risk of developing preterm preeclampsia. Simultaneously, a relatively low level of IGFBP-1 in both the trimesters was associated with an increased risk of term, but not preterm preeclampsia.

IGFBP-1 is synthesized by the decidual stroma, and IGFBP-1 is thought to inhibit local IGF activity and reduce trophoblast invasion early in pregnancy $(4,7)$. Therefore, it has been suggested that women, who later develop preeclampsia, have low levels of circulating IGF-I and high levels of IGFBP-1 $(4,7)$. Results of studies that have tested this hypothesis, however, have not been consistent. In one study, IGFBP-1 concentration was relatively low in early pregnancy before the development of preeclampsia, leading the authors to conclude that IGFBP-1-induced inhibition of IGF activity is not likely to cause the impaired trophoblast invasion observed in preeclampsia (7). In another study, both IGF-I and IGFBP-1 were relatively low early in pregnancy among women, who later developed preeclampsia (11), but others have found higher concentration of IGF-I and lower IGFBP-1 preceding preeclampsia (5). These studies, however, only assessed the effect of single measurements, and were unable to study longitudinal changes in IGFs between trimesters, as in our study.

Our nested case-control study was derived from nearly 30000 pregnant women (9), and provided substantially more cases of preeclampsia than other studies. Maternal serum was stored at $-20{ }^{\circ} \mathrm{C}$ for approximately 10 years before analyses. The storage time could affect serum concentrations of IGFs, but matching on storage time between cases and controls makes it unlikely that a possible deterioration differs systematically between the groups. The changes in IGFs could only be studied among women with serum collected in both the trimesters, and therefore, differences in collection patterns between cases and controls could have biased the results. However, only six cases of early onset preeclampsia delivered before 28 weeks of gestation, and they all provided blood prior to delivery. Therefore, it seems unlikely that bias in blood 
Table 2 The association (odds ratios, OR) between quartiles of concentrations of insulin-like growth factor binding protein-1 (IGFBP-1) and subsequent preeclampsia (diagnosed preterm or at term).

\begin{tabular}{|c|c|c|c|c|c|c|c|}
\hline \multirow[b]{2}{*}{ IGFBP-1 (ng/ml) } & \multirow[b]{2}{*}{ Controls } & \multicolumn{3}{|c|}{ Preterm $^{a}$ preeclampsia } & \multicolumn{3}{|c|}{ Term $^{a}$ preeclampsia } \\
\hline & & Cases & $\mathrm{OR}^{\mathrm{b}}$ & $(95 \% \mathrm{Cl})$ & Cases & $\mathrm{OR}^{\mathrm{b}}$ & $(95 \% \mathrm{Cl})$ \\
\hline \multicolumn{8}{|l|}{ First trimester } \\
\hline$<24.46$ & 69 & 27 & 1.5 & $(0.7-3.3)$ & 56 & 4.0 & $(1.9-8.4)$ \\
\hline $24.46-47.01$ & 68 & 35 & 2.1 & $(1.1-4.3)$ & 39 & 2.4 & $(1.2-4.8)$ \\
\hline $47.02-82.38$ & 69 & 25 & 1.5 & $(0.7-3.1)$ & 28 & 1.8 & $(0.9-3.6)$ \\
\hline$\geq 82.39$ & 68 & 20 & 1.0 & (Reference) & 20 & 1.0 & (Reference) \\
\hline \multicolumn{8}{|l|}{ Second trimester } \\
\hline$<92.85$ & 72 & 43 & 1.7 & $(0.9-3.1)$ & 50 & 2.3 & $(1.2-4.4)$ \\
\hline $92.85-128.75$ & 71 & 15 & 0.6 & $(0.3-1.2)$ & 37 & 1.6 & $(0.9-3.2)$ \\
\hline $128.76-169.90$ & 72 & 24 & 0.9 & $(0.5-1.8)$ & 23 & 1.0 & $(0.5-2.1)$ \\
\hline$\geq 169.91$ & 71 & 26 & 1.0 & (Reference) & 20 & 1.0 & (Reference) \\
\hline \multicolumn{8}{|c|}{$\begin{array}{l}\text { Change from first to } \\
\text { second trimester }\end{array}$} \\
\hline$<36.08$ & 24 & 9 & 1.0 & (Reference) & 20 & 1.0 & (Reference) \\
\hline $36.08-70.36$ & 23 & 16 & 1.9 & $(0.6-6.3)$ & 9 & 0.6 & $(0.2-1.7)$ \\
\hline $70.37-105.37$ & 23 & 5 & 0.6 & $(0.2-2.3)$ & 7 & 0.3 & $(0.1-1.0)$ \\
\hline$\geq 105.38$ & 24 & 12 & 2.2 & $(0.6-7.4)$ & 11 & 0.6 & $(0.2-1.6)$ \\
\hline
\end{tabular}

$\mathrm{Cl}$ denotes confidence interval.

aPreterm preeclampsia; diagnosed at gestational week 37 or earlier. Term preeclampsia; diagnosed after week 37.

${ }^{b}$ Adjusted for gestational week of blood sampling (continuous), maternal age $(<25,25-29,30-34, \geq 35$ years), and parity (1, 2, $\geq 3)$.

collection pattern could have substantially influenced the results.

The influence of potentially confounding factors should also be considered. In the statistical analyses, we adjusted for differences in maternal age and parity, since these factors are related to preeclampsia risk. In the analyses of single measurements of IGF-I and IGFBP-1 within each trimester, we also adjusted for differences in the pregnancy week at blood sampling. In the analyses of changes between trimesters, adjustment was made for the differences in time between blood collections. The results remained essentially unchanged after these adjustments.

We found that a high increase in IGF-I from the first to the second trimester was related to a particularly high risk of preterm preeclampsia, and a moderate increase in term preeclampsia. A compromised placental function renders the fetus at risk, and it seems plausible that compensatory mechanisms are released to counteract possible adverse effects. Placental GH is exclusively expressed in the syncytiotrophoblast, and released to the maternal circulation with increasing concentrations from the 7 th or 8 th week of gestation $(3,12,13)$. Placental GH suppresses maternal pituitary GH production and regulates maternal levels of IGF-I in pregnancy. It has been shown that low levels of placental $\mathrm{GH}$ are associated with restricted fetal growth, most likely mediated by reduced levels of IGF-I (3, 14). However, a recent study demonstrated elevated second trimester levels of placental GH in women, who later developed preeclampsia associated with intrauterine growth restriction (15). In these pregnancies, the levels of placental GH are later likely to decrease due to the placental insufficiency that precedes preeclampsia, accompanied by detrimental effects on fetal growth.
Unfortunately, placental GH has not been measured in our study.

The strong positive association that we found between the increase in IGF-I from the first to the second trimester and subsequent risk of preterm preeclampsia may be attributed to a compensatory mechanism released by a dysfunctional placenta, resulting in an increased IGF bioactivity via increased placental GH secretion from the syncytiotrophoblasts.

We also found that low levels of IGFBP-1, both in the first and in the second trimesters, were associated with an increased risk of preeclampsia; however, the association was substantially stronger for term than for preterm preeclampsia. Previous studies have suggested that term and preterm preeclampsia may represent different disease entities. Underlying placental disease, accompanied by a restricted growth of the fetus, appears to be a typical feature of preterm preeclampsia (16), whereas preeclampsia diagnosed at term may also reflect metabolic aberrations in the mother, including characteristics that increase her later risk of diabetes and cardiovascular disease (17).

In the non-pregnant state, relatively low levels of IGFBP-1 have been associated with a higher prevalence of metabolic syndrome/prediabetes (18). Our finding that low levels of IGFBP-1 were associated with an increased risk of term, but not preterm preeclampsia, may therefore reflect that women with metabolic aberrations, including obesity, are at an increased risk of preeclampsia with onset at term. Possibly, this type of preeclampsia differs etiologically from the clinically severe form that is often diagnosed before term.

In conclusion, these data show that an increase in circulating IGF-I from the first to the second trimester strongly increases the risk of preterm preeclampsia, and 
low levels of IGFBP-1, both in the first and in the second trimesters, are associated with an increased risk of term, but not preterm preeclampsia.

\section{Acknowledgements}

This study was supported financially by the Norwegian Institute of Public Health, the Norwegian Research Council, and the Eastern Health Authority of Norway ('Helse Øst'). There is no conflict of interest related to this work. Contributors: Lars J Vatten and Anne Eskild conceived the idea, participated in the analyses, and wrote the paper. Tom I L Nilsen did the statistical analyses and interpreted the results. Stig Jeansson was responsible for the biochemical analyses, and interpreted the results. Pål A Jenum conceived the original study and participated in interpretation of the results. All authors have read and approved the final version of the manuscript. Anne Eskild has access to all data of this study and is guarantor.

\section{References}

1 Roberts JM \& Lain KY. Recent insights into the pathogenesis of pre-eclampsia. Placenta 200223 359-372.

2 Maynard SE, Min JY, Merchan J, Lim KH, Li J, Mondal S, Libermann TA, Morgan JP, Sellke FW, Stillman IE, Epstein FH, Sukhatme VP \& Karumanchi SA. Excess placental soluble fms-like tyrosine kinase 1 (sFlt1) may contribute to endothelial dysfunction, hypertension, and proteinuria in preeclampsia. Journal of Clinical Investigation 2003111 649-658.

3 Chellakooty M, Vangsgaard K, Larsen T, Scheike T, Falck-Larsen J, Legarth J, Andersson AM, Main KM, Skakkebaek NE \& Juul A. A longitudinal study of intrauterine growth and the placental growth hormone (GH)-insulin-like growth factor I axis in maternal circulation: association between placental GH and fetal growth. Journal of Clinical Endocrinology and Metabolism 200489 384-391.

4 Giudice LC, Martina NA, Crystal RA, Tazuke S \& Druzin M. Insulinlike growth factor binding protein-1 at the maternal-fetal interface and insulin-like growth factor-I, insulin-like growth factor II, and insulin-like growth factor binding protein-1 in the circulation of women with severe preeclampsia. American Journal of Obstetrics and Gynecology 1997176 751-758.

5 Grobman WA \& Kazer RR. Serum insulin, insulin-like growth factor-I, and insulin-like growth factor binding protein-1 in women who develop preeclampsia. Obstetrics and Gynecology 200197 521-526.

6 de Groot CJ, O'Brien TJ \& Taylor RN. Biochemical evidence of impaired trophoblast invasion of decidual stroma in women destined to have preeclampsia. American Journal of Obstetrics and Gynecology 1996175 24-29.
7 Anim-Nyame N, Hills FA, Sooranna SR, Steer PJ \& Johnsen MR. A longitudinal study of maternal plasma insulin-like growth factor bindng protein-1 concentrations during normal pregnancy and pregnancies complicated by preeclampsia. Human Reproduction $2000152215-2219$.

8 Hietala R, Pohja-Nylander P, Rutanen EM \& Laatikainen T. Serum insulin-like growth factor binding protein-1 at 16 weeks and subsequent preeclampsia. Obstetrics and Gynecology 200095 185-189.

9 Jenum PA, Stray-Pedersen B, Melby KK, Kapperud G, Whitelaw A, Eskild A \& Eng J. Incidence of Toxoplasma gondii infection in 35940 pregnant women in Norway and pregnancy outcome for infected women. Journal of Clinical Microbiology 199836 2900-2906.

10 Chan JM, Stampfer MJ, Giovannuci E, Gann PH, Ma J, Wilkinson P, Hennekens CH \& Pollak M. Plasma insulin-like growth factor-I and prostate cancer risk: a prospective study. Science $1998 \mathbf{2 7 9}$ 563-566.

11 Ning Y, Williams MA, Vadachkoria S, Muy-Rivera M, Frederick IO \& Luthy DA. Maternal plasma concentrations of insulin-like growth factor-I and insulin-like growth factor-binding protein-1 in early pregnancy and subsequent risk of preeclampsia. Clinical Biochemistry 200437 968-973.

12 Lonberg U, Damm P, Andersson AM, Main KM, Chellakooty M, Lauenborg J, Skakkebaek NE \& Juul A. Increase in maternal placental growth hormone during pregnancy and disappearance during parturition in normal and growth hormone-deficient pregnancies. American Journal of Obstetrics and Gynecology 2003 $188247-251$.

13 Chellakooty M, Skibsted L, Skouby SO, Andersson AM, Petersen JH, Main KM, Skakkebaek NE \& Juul A. Longitudinal study of serum placental GH in 455 normal pregnancies: correlation to gestational age, fetal gender, and weight. Journal of Clinical Endocrinology and Metabolism $2002872734-2739$.

14 Caufriez A, Frankenne F, Hennen G \& Copinschi G. Regulation of maternal IGF-I by placental GH in normal and abnormal human pregnancies. American Journal of Physiology $1993 \mathbf{2 6 5}$ E572-E577.

15 Papadopoulou E, Sifakis S, Giahnakis E, Fragouli Y, Karkavitsas N, Koumantakis E \& Kalmanti M. Increased human placental growth hormone at midtrimester pregnancies may be an index of intrauterine growth retardation related to preeclampsia. Growth Hormone and IGF Research 200616 290-296.

16 Vatten LJ \& Skjærven R. Is preeclampsia more than one disease? British Journal of Obstetrics and Gynaecology $2004111298-302$.

17 Irgens HU, Reisaeter L, Irgens LM \& Lie RT. Long term mortality of mothers and fathers after pre-eclampsia: population-based cohort study. BMJ 2001323 1213-1217.

18 Kalme T, Seppala M, Qiao Q, Koistinen R, Nissinen A, Harrela M, Loukovaara M, Leinonen P \& Tuomilehto J. Sex-hormone-binding globulin and insulin-like growth factor binding protein-1 as indicators of metabolic syndrome, cardiovascular risk, and mortality in elderly men. Journal of Clinical Endocrinology and Metabolism 200590 1550-1556.

Received 13 August 2007

Accepted 7 October 2007 